\title{
MODERNIZAÇÃO DA AGRICULTURA NA NOVA FRONTEIRA AGRÍCOLA DO BRASIL: MAPITOBA E SUDESTE DO PARÁ
}

\author{
Elizangela Beckmann* \\ Antônio Cordeiro de Santana**
}

RESUMO: A modernização da produção agrícola das microrregiões do acrônimo de MAPITOBA e do Sudeste do Pará derivou das combinações entre máquinas e equipamentos mecânicos e biotecnologia com as variáveis relacionadas à educação, e a técnicas de cultivo tradicionais e modernas. Assim, foram identificados e analisados os fatores que determinam a modernização da agricultura e apresentada sua configuração nas 38 microrregiões que compõem a área em estudo. Como método, utilizou-se a Análise Fatorial para extrair os fatores e hierarquizar as microrregiões de acordo com o nível de modernização. Foram identificados três fatores responsáveis pela modernização agrícola de MAPITOBA e do Sudeste do Pará e, dentre estes, o mais eficiente foi o fator de produção, relacionado à educação, investimento e mão de obra, enquanto o fator relacionado às técnicas modernas de cultivo foi o menos eficiente para a maioria das microrregiões. $\mathrm{O}$ nível de modernização apresentado pela maioria das microrregiões foi baixo, sendo que nenhuma obteve índice alto, o que se justifica pela presença recente da agricultura nesta nova fronteira agrícola do país e por ainda ser extensiva e ter distribuição tecnológica focada em determinados locais. Os resultados obtidos neste estudo permitem verificar os pontos fortes e fracos relacionados à modernização da agricultura, auxiliando em ações condizentes com o contexto atual de cada microrregião.

PALAVRAS-CHAVE: Agricultura; Análise fatorial; Tecnologia.

\section{MODERNIZATION OF AGRICULTURE IN THE NEW AGRICUL- TURAL FRONTIER OF BRAZIL: MAPITOBA AND SOUTHEAST OF PARÁ}

ABSTRACT: The modernization of agricultural production of micro-regions of the acronym of MAPITOBA and Southeast of Pará derived from combinations of machi-

\footnotetext{
"Doutorado em Ciências Agrárias pela Universidade Federal Rural da Amazônia. Brasil.

E-mail: elizangela.beckmann@hotmail.com

** Doutorado em Economia Aplicada pela Universidade Federal de Viçosa (1993). Docente Titular da Universidade Federal Rural da Amazônia. Brasil.
} 
nes and mechanical equipment and biotechnology with variables related to education, and traditional and modern farming techniques. So, were identified and analyzed the factors that determine the modernization of agriculture and presented its configuration in 38 micro-regions that make up the area of this study. As a method, it used factor analysis to extract the factors and tier micro-regions according to the level of modernization. It was identified three factors responsible for the agricultural modernization of MAPITOBA and Southeast of Pará and, among these, the most efficient was the production factor, related to education, investment and labor, while the factor related to the modern techniques of cultivation was the least efficient for most micro-regions. The level of modernization presented in most regions was low, and no high-index, which gained is justified by the recent presence of agriculture in this new agricultural frontier of the country and still be extended and have technological distribution focused on certain sites. The results obtained in this study allow to verify the strengths and weaknesses related to modernization of agriculture, assisting in actions consistent with the current context of each micro-region.

KEY WORDS: Agriculture; Factor analysis; Technology.

\section{INTRODUÇÃO}

O território brasileiro está em constante transformação, principalmente quando se fala em expansão da fronteira agrícola no cerrado, a qual ocorre acompanhada de modernas técnicas, equipamentos e biotecnologia. Historicamente, considera-se que a modernização da agricultura brasileira iniciou com a Revolução Verde a partir das décadas de 1960 e 1970, quando o governo incentivava o desenvolvimento da pesquisa e formação de pesquisadores por meio de cursos de pós-graduação, resultando em uma evolução em tecnologias de sementes adaptadas aos diferentes climas do país e produtos para correção de fertilidade de solos, focando sempre no cerrado brasileiro, cujo território plano e extenso seria propício para o avanço da agropecuária (ALVES; CONTINI; HAINZELIN, 2005).

Para Castillo (2007) a modernização da agricultura brasileira se divide em duas etapas. A primeira, entre 1960 e 1970, se caracteriza pela consolidação do Complexo Agroindustrial, em que agricultura e indústria se aproximam e usufruem de benefícios fiscais, subsídios, linhas de crédito, etc., tendo ainda apoio à produção 
tecnológica com uso de biotecnologia e internalização de indústrias de bens de capital e de produção agrícola (MULLER, 1989). A segunda etapa, considerada atual, tem como foco a consolidação da produção de commodities. Iniciou-se a partir da década de 1980, quando mediante as dificuldades políticas e econômicas do país, um novo perfil político agrícola surge, em que o Estado renuncia o comando produtivo e as grandes empresas agrícolas passam a ter forte atuação no setor, o que Santos (2000) chama de agricultura científica globalizada. Foi nesse período que se iniciou a expansão agrícola em Mato Grosso, hoje maior produtor de soja do país. E, mais recentemente, a fronteira agrícola vem expandindo em direção ao Norte e Nordeste do país.

Como fronteira agrícola se entendem as áreas de expansão da agropecuária sobre o meio ambiente. Um conceito mais atual é o de fronteira agrícola moderna, que Castillo (2007, p. 38) define como:

[...] áreas ocupadas por atividades agrícolas com alto conteúdo tecnológico e organizacional (em termos de uso de insumos e maquinário, formas de crédito e comercialização, armazenamento, beneficiamento e transporte) em substituição à pecuária extensiva, a formas tradicionais de cultura (particularmente a pequena produção familiar de origem ancestral ou de frentes de ocupação) e / ou à cobertura vegetal original.

Esta expansão da fronteira com a moderna agricultura altera o padrão técnico da produção regional, sendo a tecnologia geralmente vinculada a determinados grupos econômicos, os quais mudam as relações de produção na sua área de expansão, modificando as estruturas econômicas, sociais e culturais. A ocupação das novas terras inicia com posseiros e, depois, passa a ter atuação de grandes fazendeiros vindos geralmente das regióes Sul e Sudeste do país, os quais trazem consigo os fatores de produção (capital e trabalho) necessários para produzir, dado que o fator terra é considerado mais barato nestas regiões (BERNARDES, 2002).

Pode-se dizer que a ocupação destes espaços ocorre a partir de 1990 pela chamada "frente pioneira", através do pioneiro inovador, o qual induz a modernização com instauração de máquinas e de técnicas avançadas, tendo a ideologia de que leva o progresso a locais considerados atrasados. Assim, a partir desta frente se instalam empresas imobiliárias, ferrovias, bancos e se inicia a comercialização nestes 
locais (MARTINS, 1975).

Atualmente, a chamada nova fronteira agrícola do Brasil constitui-se pela região formada por parte dos Estados do Maranhão, Piauí e Bahia, e por todo o território do Tocantins, sendo conhecida pelo acrônimo de MAPITOBA. Esta região é formada por 31 microrregiões. Além deste território, o Sudeste do Pará também vem sendo foco da expansão agrícola do país, sendo que inclui sete microrregiões, fazendo divisa com Tocantins (MIRANDA; MAGALHÃES; CARVALHO, 2014; IBGE, 2016).

Consideram-se estas regiões locais cuja expansão da produção agrícola já inicia com técnicas modernas e não necessariamente envolve a lógica madeira-pecuária-agricultura, dado que desde o início se substituem os pastos naturais de cerrado por cultivos agrícolas de alta rentabilidade e intensivos em tecnologia, como a soja por exemplo (MIRANDA; MAGALHÃES; CARVALHO, 2014b).

Conforme menciona Frederico (2011), o cerrado possui vantagens para produção agrícola moderna, uma vez que permite dois cultivos anuais, tem duas estações bem definidas (chuva e seca), constitui-se de áreas planas e solos profundos, além de intensa luminosidade. Porém, apesar de ser no mesmo bioma, o deslocamento para regiões de cerrado, que ocorre intensivo em tecnologia e capital, torna mais complexa a configuração e as exigências tecnológicas, pois a disposição de recursos naturais não é homogênea, exigindo adaptação e integração de muitas técnicas. Exige-se, nesse novo momento de expansão territorial, cada vez mais mecanismos complexos de tecnologia e gestão, a fim de aumentar a produtividade dos fatores de produção (BUAINAIN et al., 2014).

$\mathrm{Na}$ literatura, não se tem trabalhos que tratem da modernização agrícola destes locais em conjunto e, são ainda mais escassos os focados nas microrregiões, sendo restrita a trabalhos que tratam de um ou outro Estado mencionado. Destacam-se trabalhos direcionados às questões territoriais, tais como Alves (2005), que trata da mobilidade sulista e a expansão da fronteira agrícola no Nordeste brasileiro, trazendo a configuração local e os municípios que se destacam nos Estados de Maranhão, Bahia e Piauí, sendo mostrado pelo autor que os sulistas são os responsáveis pela moderna agricultura local.

O mesmo autor, Alves (2006), em sua tese de doutorado trata da modernização nos cerrados do Piauí, mas também com foco nas questões territoriais, sem 
tratar de indicadores e variáveis modernas do Censo. Dentre os trabalhos que tratam da modernização utilizando-se de dados do Censo e tendo como método a Análise Fatorial, tem-se Costa et al. (2012), cujo resultado traz um ranking dos Estados brasileiros por nível de modernização em três fatores. No fator relacionado ao uso de tecnologia em relação à mão de obra, Tocantins ficou em oitavo lugar e, no fator novas tecnologias de logística e transporte, Pará e Piauí ficaram, respectivamente, em terceiro e oitavo lugar, o que se justifica pela expansão agrícola considerada recente nestes Estados. Como conclusão, os autores classificam os Estados do Norte e Nordeste como tendo nível baixo de modernização, devido à alta concentração fundiária e às diferenças históricas entre estes e os demais do país.

Corrêa e Figueiredo (2006) tratam a modernização a partir de dois fatores, intensidade de uso do capital e produtividade, dos quais o primeiro se mostrou positivo para o Tocantins, indicando alto uso de maquinários e investimento no Estado, enquanto os demais Estados aqui considerados (Maranhão, Bahia, Piauí e Pará) tiveram sinal negativo nos dois fatores.

Logo, a falta de estudos da região e sua importância atual para a economia do país são motivadores para esta pesquisa. Os cultivos agrícolas que envolvem as técnicas modernas e que se destacam nestas regiões são a soja, o milho, a cana-de-açúcar, o arroz e o algodão, culturas que historicamente avançam território e trazem consigo inovações tecnológicas. Dentre os Estados mencionados e suas 38 microrregiões, entre 2006 e 2014 a área destes cultivos somados saiu de 3.507.143 para 5.629.757 hectares (ha), um aumento de 60\% em oito anos. Já em termos de toneladas produzidas, em 2006 eram 11.447.956 toneladas passando em 2014 para 24.475.128 toneladas, um incremento de 113\%. Os Estados cuja soma dos cinco cultivos se destacam nas microrregiões consideradas são Maranhão e Bahia, representando juntos $70,86 \%$ da produção das 38 microrregiões de MAPITOBA e Sudeste do PA em 2006 e 57,28\% em 2014 (IBGE, 2016).

Esta evolução nos cultivos em novas áreas vem acompanhada da modernização no campo, o que torna relevante incluir no modelo as variáveis relacionadas a isso, tais como educação, uso de maquinário e técnicas mitigadoras de impactos ambientais no cultivo. Assim, com esta pesquisa busca-se responder se essas variáveis modernas interferem na modernização agrícola das microrregiões de MAPITOBA e Sudeste do Pará. 
Diante deste contexto de expansão de território e aumento da produção de cultivos relacionados à agricultura moderna, torna-se relevante verificar o nível de modernização das microrregiões que compõem o acrônimo MAPITOBA e o Sudeste do Pará, a fim de identificar especificamente quais os fatores que envolvem a agricultura nestes locais e os pontos fortes e fracos a serem fortalecidos e desenvolvidos por cada microrregião.

\section{MATERIAL E MÉTODOS}

A base de dados utilizada para encontrar os fatores e definir o nível de modernização agrícola para as microrregiões da região chamada MAPITOBA e as microrregiões do Sudeste do Pará foi obtida no Censo Agropecuário de 2006, disponibilizado pelo Instituto Brasileiro de Geografia e Estatística (IBGE, 2016). A amostra compõe-se de 38 microrregiões, das quais 15 são do Estado do Maranhão, quatro do Piauí, oito do Tocantins (todas), quatro da Bahia e sete do Sudeste do Pará. Não foram consideradas todas as microrregiões dos Estados devido a serem apenas nestas que a agricultura vem se desenvolvendo com maior ênfase nos últimos anos, sendo consideradas como a nova fronteira agrícola do Brasil.

Sendo apenas 38 observações, selecionou-se oito variáveis do Censo, observando as indicações de Hair et al. (2009), de pelo menos cinco observações por variável. A padronização das variáveis se deu pela Área de Lavoura Temporária (ALT), que inclui apenas a área cultivada de lavouras temporárias em hectares, e pelo Número Total de Estabelecimentos (TE), que representa o número total de estabelecimentos relacionado com cada variável.

As variáveis selecionadas no Censo Agropecuário foram: $\mathbf{X}_{1}$ - Número de tratores/(ALT); $\mathbf{X}_{2}$-Educação (pessoa que administra o estabelecimento com mais de 8 anos de estudo)/(ALT); $\mathbf{X}_{3}$ - Valor do investimento (em R $\left.\$ 1000\right) /\left(\right.$ ALT); $\mathbf{X}_{4}$ - Estabelecimentos com uso de irrigação/(TE); $\mathbf{X}_{5}$ - Estabelecimentos com cultivo convencional (aração mais gradagem ou gradagem profunda) $/(\mathrm{TE}) ; \mathbf{X}_{6}$ - Estabelecimentos com cultivo mínimo (só gradagem)/(TE); $\mathbf{X}_{7}$ - Estabelecimentos com plantio direto na palha/(TE); $\mathbf{X}_{8}$ - Estabelecimentos com agricultura orgânica (certificado por entidade credenciada $) /(\mathrm{TE})$. 
O método escolhido foi a Análise Fatorial (AF), devido ao caráter multidimensional aplicado ao conceito de modernização agrícola considerado neste trabalho. Os dados foram processados no software Statistical Package of Social Science - SPSS (IBM Statistic 18). A Análise Fatorial é uma ferramenta que auxilia resumir as informações do fenômeno em estudo, no caso a modernização agrícola, em um número de fatores menor do que o número de variáveis e sem perda de informação (SANTANA et al., 2014).

$\mathrm{Na}$ Análise Fatorial assume-se que um grupo de variáveis tem alta correlação entre si e baixa correlação entre variáveis de outros grupos, definindo então um único fator, também chamado dimensão latente. Os fatores formados permitem visualizar a modernização na região em estudo e assim vislumbrar pontos fortes e fracos a serem priorizados (SANTANA et al., 2014).

Quanto a variância, cada variável foi definida como uma combinação linear dos fatores comuns que irão explicar a parcela da variância contida em cada uma, mais um desvio que resume a parcela da variância total não explicada por esses fatores. Assim, tem-se a comunalidade, como é chamada a parcela da variância explicada pelos fatores comuns, que pode variar de 0 a 1 , sendo que valores próximos de 0 (zero) indicam que os fatores comuns não explicam a variância e, valores próximos de 1 (um), indicam que a variância de todas as variáveis é explicada pelos fatores comuns (HAIR et al., 2009).

A forma matricial do modelo de Análise Fatorial, conforme Dillon e Goldstein (1984), é:

$$
X=\left[\begin{array}{c}
X_{1} \\
X_{2} \\
\vdots \\
X_{p}
\end{array}\right] ; \Lambda=\left[\begin{array}{cccc}
\lambda_{11} & \lambda_{12} & \cdots & \lambda_{1 q} \\
\lambda_{21} & \lambda_{22} & \cdots & \lambda_{2 q} \\
\vdots & \vdots & \vdots & \vdots \\
\lambda_{p 1} & \lambda_{p 2} & \cdots & \lambda_{p q}
\end{array}\right] ; F=\left[\begin{array}{c}
f_{1} \\
f_{2} \\
\vdots \\
f_{q}
\end{array}\right] ; E=\left[\begin{array}{c}
e_{1} \\
e_{2} \\
\vdots \\
e_{p}
\end{array}\right]
$$

Em que: $\mathrm{X}=$ é o $\mathrm{p}$-dimensional vetor de variáveis originais; $X^{\prime}=\left(\mathrm{x}_{1}, \mathrm{x}_{2}, \ldots\right.$, $\left.\mathrm{x}_{\mathrm{p}}\right) ; \mathrm{F}=$ é o q-dimensional de fatores comuns; $F^{\prime}=\left(\mathrm{f}_{1}, \mathrm{f}_{2}, \ldots, \mathrm{f}_{\mathrm{q}}\right) ; \mathrm{E}=$ é o p-dimensional de fatores únicos; $E^{\prime}=\left(\mathrm{e}_{1}, \mathrm{e}_{2}, \ldots, \mathrm{e}_{\mathrm{p}}\right)$; = é a matriz $(\mathrm{p}, \mathrm{q}) \mathrm{de}$ constantes desconhecidas. 
Pressupõe-se que os fatores latentes são não correlacionados entre si e com todos os fatores comuns, ou seja, os erros são não correlacionados aos fatores, $E(\varepsilon)$ $=E(F)=0$ e $\operatorname{Cov}(\varepsilon, F)=0$. Porém, a estrutura inicial utilizada para determinar a matriz de cargas fatoriais pode não fornecer um padrão significativo de cargas das variáveis, por isso não é definitiva (JOHNSON; WICHERN, 1992 apud GAMA et al., 2007; SANTANA et al., 2014). Para contornar este problema, utilizou-se o método Varimax de rotação ortogonal dos fatores. O objetivo da rotação é redistribuir a variância dos primeiros fatores para os demais e atingir um padrão fatorial mais simples e teoricamente mais significativo (HAIR et al., 2009; SANTANA et al., 2014).

$\mathrm{A}$ adequação da amostra à AF foi realizada através dos testes de Kaiser-Meyer-Olkin (KMO), que se baseia no princípio de que a inversa da matriz de correlação se aproxima da matriz diagonal, para tanto compara as correlações entre as variáveis observáveis, e o teste de Bartlett, o qual avalia a significância geral da matriz de correlação, testando a hipótese nula de que a matriz de correlação é uma matriz identidade. Desta forma, o KMO maior que 0,5 indica adequação da técnica e quanto mais próximo a 1 (um) indica perfeita adequação dos dados para Análise Fatorial (MOORI; ZILBER, 2003; HAIR et al., 2009). A significância do teste de Bartlett a $1 \%$ permite rejeitar a hipótese nula, indicando que a amostra se adequa à análise. A definição das variáveis relacionadas a cada fator foi feita com base na magnitude e significância das cargas fatoriais, assim cada variável pertence ao fator em que sua carga for mais alta (SANTANA et al., 2014).

A partir dos fatores comuns extraídos, foram estimados os escores fatoriais para cada uma das microrregiões estudadas. Com estes escores calcula-se um Índice de Modernização Agrícola (IMA), que permite hierarquizar as microrregiões de acordo com o grau de modernização. Antes de calcular o IMA é necessário padronizar os escores fatoriais obtidos através da AF, para se obter valores positivos dos escores originais sendo possível hierarquizar os municípios, dado que os valores do IMA estão entre zero e um. A fórmula para a padronização dos escores é:

$$
\mathrm{FP}_{\mathrm{i}}=\left(\frac{F_{i}-F_{\min }}{F_{\max }-F_{\min }}\right)
$$


Em que: $\mathrm{F}_{\mathrm{i}}=$ escore fatorial original; $\mathrm{F}_{\min }=$ valor mínimo observado para os escores fatoriais; $\mathrm{F}_{\max }=$ valor máximo observado para os escores fatoriais.

Considera-se que o Índice de Modernização Agrícola é uma combinação linear dos escores fatoriais e a proporção da variância explicada por cada fator em relação à variância comum (GAMA et al., 2007). É representado matematicamente por:

$$
I M A_{i}=\sum_{j=1}^{q}\left(\frac{\lambda_{j}}{\sum_{j} \lambda_{j}} F P_{i j}\right)
$$

Em que: $\lambda=$ é a variância explicada por cada fator; $\Sigma \lambda=$ é a soma total da variância explicada pelo conjunto de fatores comuns; FP ( $\mathrm{i}=1,2, \ldots$ n) = escore fatorial padronizado.

Assim, com base nas definições de Gama et al. (2007), valores do IMA igual ou maior que 0,70 são considerados altos, se referindo às microrregiões com alto grau de modernização agrícola; valores entre 0,40 e 0,69 considera-se a microrregião intermediária em modernização agrícola; e valores abaixo de 0,40 são microrregiões que apresentaram baixo IMA.

\section{RESULTADOS E DISCUSSÃO}

A delimitação do território conhecido pelo acrônimo MAPITOBA foi feita pelo Grupo de Inteligência Territorial da Embrapa (GITE), sendo composta por 31 das 76 microrregiões que compõem seus Estados, das quais quinze são do Maranhão, quatro do Piauí, oito do Tocantins e quatro da Bahia. Do território de 73 milhões de hectares da região MAPITOBA, 33\% pertencem ao Maranhão, 38\% ao Tocantins, $11 \%$ ao Piauí e 18\% à Bahia, apresentando no ano de 2006, 324.324 estabelecimentos agropecuários, ou seja, $24 \%$ do total de estabelecimentos quando consideradas todas as microrregióes destes Estados e ocupando uma área de 33.742.543,92 hecta- 
res, equivalente a $51 \%$ da área de todos os estabelecimentos dos Estados mencionados (MIRANDA; MAGALHÃES; CARVALHO, 2014; IBGE, 2016).

Nas sete microrregiões do Sudeste do Estado do Pará, também consideradas locais de expansão da fronteira agrícola moderna no país, as quais fazem divisa com Tocantins, somavam-se em 2006, 52.767 estabelecimentos agropecuários com 11.092.678,78 hectares, representando respectivamente $23,77 \%$ dos estabelecimentos agropecuários do Pará (222.028) e 49,38\% (22.466.026 ha) da área destes no Estado (IBGE, 2006).

A partir da análise fatorial o teste Kaiser-Meyer-Olkin demonstrou a adequação amostral para a análise $(\mathrm{KMO}=0,685)$ e todos os valores de KMO para os itens individualmente (diagonal da matriz anti-imagem) foram maiores que 0,6. O teste de esfericidade de Bartlett (qui-quadrado (190) = 200,410, p menor que 0,001), indicou que as correlações entre as variáveis são suficientes para a realização da análise.

Foram extraídos três fatores a partir das oito variáveis, os quais explicam juntos $85,44 \%$ da variância total, sendo um valor satisfatório. O primeiro fator comum extraído possui maior importância e explica 32,60\% da variância total dos dados, incluindo três variáveis; o segundo fator explica 30,31\%, agrupando também três variáveis; e, o terceiro fator, explica 22,51\% a variância total dos dados, incluindo duas variáveis. Todas as comunalidades foram acima de 0,7 (Tabela 1), sendo então aceitáveis para a inclusão no modelo estimado. A matriz de cargas fatoriais do modelo estimado, de acordo com sua significância, permite associar as variáveis a cada dimensão latente (Tabela 1).

$\mathrm{O}$ primeiro fator incluiu três variáveis, todas com carga positiva e maior que 0,9, sendo elas: $\mathbf{X}_{1}$ - Número de tratores/(ALT); $\mathbf{X}_{2}$ - Educação (pessoa que administra o estabelecimento com mais de 8 anos de estudo)/(ALT); $\mathbf{X}_{3}$-Valor do investimento (em $\mathrm{R} \$ 1000) /(\mathrm{ALT})$. Tais variáveis se relacionam à mão de obra, investimento e mecanização da agricultura, e as cargas altas encontradas indicam que o uso de mão de obra qualificada, o investimento e a mecanização acompanham a expansão desta fronteira agrícola. Diante disso, tal fator foi nomeado Fator Produtivo.

Neste fator, $31,58 \%$ das microrregióes tiveram escore positivo e $68,42 \%$ apresentaram escore negativo, ou seja, há uma necessidade de qualificação da mão de obra das microrregiões de MAPITOBA e do Sudeste do Pará, além de maior inves- 
timento em tecnologia, seja com maquinários ou técnicas inovadoras. O maior escore neste fator foi na microrregião de Redenção (PA). De acordo com o Censo Agropecuário, em 2006, as 38 microrregiões tinham 27.412 tratores e 1.293 .023 pessoas ocupadas na agropecuária, enquanto o investimento foi um total de $\mathrm{R} \$ 1.844 .406,67$ milhão no setor agropecuário. As pessoas a frente dos estabelecimentos com pelo menos ensino fundamental somaram, em 2006, 46.387 indivíduos.

Tabela 1. Matriz de cargas fatoriais rotacionadas da modernização agrícola das microrregiões de MAPITOBA e do Sudeste do Pará em 2006

\begin{tabular}{|c|c|c|c|c|}
\hline Variáveis & Fator 1 & Fator 2 & Fator 3 & Comunalidade \\
\hline $\mathbf{X}_{1}$ - Número de tratores/(ALT) & 0,935 & 0,051 & $-0,194$ & 0,914 \\
\hline $\begin{array}{l}\mathbf{X}_{2} \text { - Educação (pessoa que administra o } \\
\text { estabelecimento com mais de } 8 \text { anos de } \\
\text { estudo)/(ALT) }\end{array}$ & 0,916 & 0,016 & $-0,097$ & 0,849 \\
\hline $\begin{array}{l}\mathbf{X}_{3} \text { - Valor do investimento }(\mathrm{em} \mathrm{R} \$ 1000) / \\
(\text { ALT) }\end{array}$ & 0,913 & $-0,126$ & $-0,037$ & 0,851 \\
\hline $\begin{array}{l}\mathbf{X}_{4} \text { - Estabelecimentos com uso de irrigação/ } \\
\text { (TE) }\end{array}$ & $-0,036$ & 0,694 & 0,608 & 0,852 \\
\hline $\begin{array}{l}\mathbf{X}_{5} \text { - Estabelecimentos com cultivo conven- } \\
\text { cional (aração mais gradagem ou gradagem } \\
\text { profunda)/(TE) }\end{array}$ & $-0,020$ & 0,929 & 0,148 & 0,885 \\
\hline $\begin{array}{l}\mathbf{X}_{6} \text { - Estabelecimentos com cultivo mínimo } \\
\text { (só gradagem)/(TE) }\end{array}$ & $-0,018$ & 0,946 & 0,066 & 0,900 \\
\hline $\begin{array}{l}\mathbf{X}_{7} \text { - Estabelecimentos com plantio direto na } \\
\text { palha/(TE) }\end{array}$ & $-0,243$ & $-0,027$ & 0,846 & 0,775 \\
\hline $\begin{array}{l}\mathbf{X}_{8} \text { - Estabelecimentos com agricultura orgâ- } \\
\text { nica (faz e é certificado por entidade creden- } \\
\text { ciada)/(TE) }\end{array}$ & $-0,029$ & 0,407 & 0,801 & 0,809 \\
\hline Variância (\%) & 32,54 & 30,76 & 22,1 & 85,39 \\
\hline
\end{tabular}

Fonte: Dados da Pesquisa.

Este fator é de grande relevância para modernização, uma vez que, conforme Vieira Filho e Silveira (2012), investir na agricultura proporciona aumento da capacidade de absorção de conhecimento externo, sendo que agricultores competem por uma melhor e mais eficiente combinação de insumos para terem vantagens 
comparativas em relação aos concorrentes.

No segundo fator agruparam-se as variáveis: $\mathbf{X}_{4}$ - Estabelecimentos com uso de irrigação/(TE); $\mathbf{X}_{5}$ - Estabelecimentos com cultivo convencional (aração mais gradagem ou gradagem profunda)/(TE); $\mathbf{X}_{6}$ - Estabelecimentos com cultivo mínimo (só gradagem)/(TE). As variáveis cultivo convencional, cultivo mínimo e uso de irrigação se relacionam às técnicas utilizadas na agricultura, sendo que enquanto cultivo convencional é uma técnica mais tradicional e antiga, cuja produtividade acaba sendo menor e as perdas de solo maiores, o cultivo mínimo e a irrigação são técnicas mais modernas, ou seja, com menor impacto ao solo e que permitem melhoria no rendimento da produção, portanto mais sustentáveis. Juntas estas variáveis representam um fator ao qual se pode denominar de Técnicas Agrícolas Tradicionais e de Baixo Impacto Ambiental. Devido às cargas fatoriais de todas as variáveis serem positivas e significativas, subentende-se que há uma mistura no uso destas técnicas nas microrregiões em análise, sendo a carga mais alta para o cultivo mínimo e a mais baixa para irrigação, o que pode se justificar por esta ter alto custo de implantação, ou pelo fato de a maior parte da região ter índices pluviométricos adequados não necessitando uso de irrigação.

Neste fator, os escores das 38 microrregiões se apresentaram positivos para $42,1 \%$ e negativos para $57,9 \%$, indicando que as técnicas tradicionais e de menor impacto ambiental estão presentes, porém por ser a maioria dos escores com sinal negativo, pode-se subentender que as técnicas tradicionais podem estar sendo substituídas pelas mais modernas. O maior escore foi na microrregião de Bom Jesus da Lapa (BA).

O terceiro e último fator agrupou as variáveis: $\mathbf{X}_{7}$ - Estabelecimentos com plantio direto na palha/(TE); $\mathbf{X}_{8}$ - Estabelecimentos com agricultura orgânica (certificado por entidade credenciada)/(TE). Incluiu duas variáveis relacionadas a métodos e alternativas de produção de menor impacto ambiental, sendo então denominado Técnicas de Agricultura Moderna. A composição deste fator indica que nas microrregiões utilizam-se técnicas de produção que visam diminuir os impactos das atividades sobre o meio ambiente.

A carga de ambas foi de 0,846 e 0,801 respectivamente, indicando que as microrregiões estão adotando boas práticas, como plantio direto, para evitar erosão 
e auxiliar na incorporação de fertilizantes e no combate de pragas, e incorporando agricultura orgânica certificada no processo de produção agrícola, visando à sustentabilidade da agricultura, que pode também estar direcionada aos agricultores familiares, característica comum nestes espaços, pois conforme Fonseca e Miranda (2014), na região MAPITOBA são mais de 865 assentamentos rurais em cerca de 3.706.699 hectares, no qual vivem aproximadamente 100 mil famílias, sendo Bom Jesus da Lapa (BA) e Alto Mearim e Grajaú (MA) as microrregiões de maior concentração destes, juntas englobam 24,89\% dos assentamentos. E, no Sudeste do Pará, são 480 assentamentos, sendo 77.311 famílias assentadas, das quais mais de 21.000 estão nos municípios de Marabá, Pacajá e Novo Repartimento.

Diante dos escores da fatorial, das 38 microrregióes analisadas 36,8\% tiveram influência positiva neste fator, o que demonstra que os produtores agrícolas da região estão utilizando as práticas agrícolas modernas alinhadas com a preservação ambiental. Porém, ainda há 63,2\% de microrregiões que precisam estar atentas e passar a adotar tais práticas, o que pode estar ocorrendo devido ao caráter ainda extensivo da produção agrícola. A microrregião de Santa Maria da Vitória (BA) teve o maior escore neste fator.

É importante mencionar que o sistema de plantio direto (SPD) faz parte do Plano ABC (Plano Setorial de Mitigação e de Adaptação às Mudanças Climáticas para a Consolidação de uma Economia de Baixa Emissão de Carbono na Agricultura) do Governo Federal, como um dos programas para mitigar os impactos ambientais entre 2011 e 2020, na medida em que contribui para redução dos Gases de Efeito Estufa (GEE) (BRASIL, 2012). E, ainda, conforme estudo feito por Marchão et al. (2016), o estoque de carbono em sistemas de plantio direto se assemelha ao do cerrado nativo, ou seja, observando áreas agrícolas de Goiás entre 2003 e 2011, os autores comprovaram que este sistema de cultivo contribui para reduzir os GEE.

A partir dos fatores identificados, observa-se que as microrregiões de MAPITOBA e do Sudeste do PA vêm se destacando na incorporação de variáveis modernas na produção agrícola, sendo importante demonstrar o comportamento de cada microrregião diante de tais fatores, para destacar quais Estados estão a frente neste contexto. 


\section{1 ÍNDICE DE MODERNIZAÇÃO AGRÍCOLA (IMA)}

Com base nos escores fatoriais, foi possível calcular o IMA das microrregiões em estudo, permitindo ranqueá-las de acordo com pontos fortes e fracos no que diz respeito à modernização da agricultura. A média do IMA para as 38 microrregiões foi de 0,2336 (Tabela 2), enquadrando-as em um nível considerado baixo para modernização agrícola. Do total de microrregiões apenas 39,5\% registraram um IMA acima da média.

Conforme metodologia, os níveis de modernização das microrregiões em estudo estão entre baixo e intermediário, pois mesmo com fatores indicando agricultura moderna, nenhuma apresentou nível alto de modernização agrícola (acima de 0,7 ). Isso pode ser explicado pelo fato de a agricultura ainda estar avançando nesta região e, devido a região ser extensa, a utilização das técnicas ainda não tinha uma distribuição homogênea e generalizada entre as microrregiões em 2006. Outro aspecto relevante é o fato de que a maioria das microrregiões incorpora apenas um ou dois dos fatores observados, tendo pelo menos um deles com carga negativa, o que contribui para a redução no IMA.

Todas apresentaram os escores fatoriais, permitindo o ranking das $38 \mathrm{mi}-$ crorregiões. Assim, a maioria das microrregiões, 89,5\%, foram classificadas com baixo nível de modernização, e 11,5\% tiveram nível de modernização intermediário. Um fato que contribuiu para isto foi a inclusão de variáveis consideradas inovadoras neste modelo, tais como a qualificação de mão de obra e as técnicas agrícolas sustentáveis e modernas, que são cada vez mais importantes devido à sustentabilidade agrícola e, no entanto, apresentam baixa distribuição entre as microrregiões.

Das quatro microrregiões em nível intermediário de modernização agrícola, duas são do Estado da Bahia e duas do Pará. Os demais Estados analisados, Maranhão, Piauí e Tocantins, tiveram todas as microrregiões com nível baixo de modernização. As microrregiões com IMA intermediário foram Santa Maria da Vitória e Cotegipe, na Bahia, e Parauapebas e Redenção, no Pará. 
Tabela 2. Valores dos escores fatoriais originais e padronizados e o Índice de Modernização Agrícola (IMA)

(Continua)

\begin{tabular}{lllrrrc}
\hline Ranking & \multicolumn{1}{c}{ Microrregião } & UF & F1 & F2 & F3 & IMA \\
\hline 1 & Santa Maria da Vitória & BA & $-0,0502$ & 2,6100 & 3,9992 & 0,6075 \\
2 & Redenção & PA & 4,0166 & $-0,5215$ & 0,0452 & 0,5156 \\
3 & Cotegipe & BA & 0,6595 & 1,4276 & 0,6071 & 0,4141 \\
4 & Parauapebas & PA & 2,7589 & $-0,3538$ & $-0,3139$ & 0,4106 \\
5 & Bom Jesus da Lapa & BA & $-0,4345$ & 3,6636 & $-1,3381$ & 0,3865 \\
6 & São Félix do Xingu & PA & 1,5582 & 0,0545 & $-0,7372$ & 0,3235 \\
7 & Araguaína & TO & 0,7780 & 0,3076 & $-0,0072$ & 0,3157 \\
8 & Imperatriz & MA & 0,6413 & 0,2484 & 0,1007 & 0,3062 \\
9 & Barreiras & BA & $-0,6457$ & 1,4476 & 0,2780 & 0,2966 \\
10 & Gurupi & TO & 0,5812 & 0,8163 & $-0,8955$ & 0,2915 \\
11 & Tucuruí & PA & 1,1840 & $-1,0134$ & 0,5082 & 0,2818 \\
12 & Bico do Papagaio & TO & 0,0884 & 0,4646 & $-0,2092$ & 0,2623 \\
13 & Alto Mearim e Grajaú & MA & $-0,1501$ & $-0,8162$ & 1,6101 & 0,2449 \\
14 & Alto Médio Gurguéia & PI & $-0,4698$ & 0,3047 & 0,5116 & 0,2430 \\
15 & Caxias & MA & $-0,3816$ & $-0,8801$ & 1,9699 & 0,2401 \\
16 & Miracema do Tocantins & TO & $-0,2790$ & 0,8248 & $-0,9171$ & 0,2234 \\
17 & Conceição do Araguaia & PA & 0,0948 & $-0,1891$ & $-0,1480$ & 0,2207 \\
18 & Médio Mearim & MA & $-0,1967$ & $-0,3573$ & 0,5221 & 0,2193 \\
19 & Dianópolis & TO & $-0,0861$ & 0,2446 & $-0,5261$ & 0,2178 \\
20 & Rio Formoso & TO & 0,0949 & 0,3250 & $-1,0306$ & 0,2126 \\
21 & Chapadas do Extremo Sul Piauiense & PI & $-0,4586$ & $-0,0392$ & 0,1320 & 0,2014 \\
22 & Marabá & PA & 0,1966 & $-0,6973$ & $-0,1700$ & 0,1925 \\
23 & Chapadas do Alto Itapecuru & MA & $-0,7165$ & 0,1980 & $-0,1091$ & 0,1856 \\
24 & Presidente Dutra & MA & $-0,2575$ & 0,0076 & $-0,6241$ & 0,1831 \\
25 & Porto Nacional & TO & $-0,3409$ & $-0,0479$ & $-0,4772$ & 0,1800 \\
26 & Itapecuru Mirim & MA & $-0,5221$ & $-1,4728$ & 1,8027 & 0,1798 \\
27 & Porto Franco & MA & $-0,3160$ & $-0,0170$ & $-0,6270$ & 0,1766 \\
28 & Bertolínia & PI & $-0,6594$ & 0,0660 & $-0,6549$ & 0,1540 \\
29 & Lençois Maranhenses & MA & $-0,6750$ & $-0,9755$ & 0,6186 & 0,1437 \\
30 & Paragominas & PA & $-0,2695$ & $-0,6268$ & $-0,5588$ & 0,1415 \\
31 & Chapadinha & MA & $-0,6163$ & $-1,0266$ & 0,4158 & 0,1348 \\
\hline & & & & & \\
& & & & & \\
14 & & & &
\end{tabular}


(Conclusão)

\begin{tabular}{|c|c|c|c|c|c|c|}
\hline Ranking & Microrregião & UF & F1 & F2 & F3 & IMA \\
\hline 32 & Jalapão & TO & $-0,6368$ & $-0,4022$ & $-0,5076$ & 0,1307 \\
\hline 33 & Chapadas das Mangabeiras & MA & $-0,7247$ & $-0,3932$ & $-0,6236$ & 0,1187 \\
\hline 34 & Codó & MA & $-0,5301$ & $-0,7481$ & $-0,5187$ & 0,1147 \\
\hline 35 & Gerais de Balsas & MA & $-0,7906$ & $-0,4966$ & $-0,4724$ & 0,1138 \\
\hline 36 & Alto Parnaíba Piauiense & PI & $-0,8163$ & $-0,5443$ & $-0,6340$ & 0,1005 \\
\hline 37 & Baixo Parnaíba Maranhense & MA & $-0,8370$ & $-0,4364$ & $-0,7613$ & 0,1001 \\
\hline 38 & Coelho Neto & MA & $-0,7914$ & $-0,9556$ & $-0,2595$ & 0,0926 \\
\hline Mínimo & & & $-0,8370$ & $-1,4728$ & $-1,3381$ & \\
\hline Máximo & & & 4,0166 & 3,6636 & 3,9992 & \\
\hline IMA Médio & & & & & & 0,2336 \\
\hline
\end{tabular}

Fonte: Dados da pesquisa.

Santa Maria da Vitória, com IMA 0,61, vem se aproximando do nível alto de modernização na agricultura, sendo a maior produtora das quatro microrregiões da Bahia, quando somados os cultivos de arroz, milho, soja, algodão e cana-de-açúcar, produziu 24,5\% do total (IBGE, 2016). Nesta, os fatores Técnicas Agrícolas Tradicionais e de Baixo Impacto Ambiental e Técnicas de Agricultura Moderna obtiveram escore positivo, enquanto o Fator de Produção se apresentou negativo, indicando a necessidade de maior qualificação da mão de obra e investimento no setor produtivo.

Já a microrregião de Redenção, pertencente ao Sudeste do Pará, em segundo lugar no ranking com IMA 0,52 , teve os fatores Técnicas de Agricultura Moderna e Fator de Produção positivos, enquanto Técnicas Agrícolas Tradicionais e de Baixo Impacto Ambiental teve escore negativo, o que pode estar atrelado ao possível fato de ser focada na grande propriedade, já com técnicas modernas de cultivo, como plantio direto. A microrregião de Cotegipe apresentou todos os fatores positivos, já a quarta colocada, Parauapebas, teve apenas escore positivo para o Fator de Produção.

Quanto às demais microrregióes (34), pode-se concluir que o fator que se apresentou com menor eficiência foi o Fator de Produção, com apenas 26,47\% (9) dos escores positivos. Já os fatores Técnicas Agrícolas Tradicionais e de Baixo 
Impacto Ambiental e Técnicas de Agricultura Moderna tiveram escore positivo em 38,24\% (13) e 29,41\% (10) das microrregióes respectivamente. Nota-se que há um equilíbrio na adoção de técnicas agrícolas tradicionais (cultivo mínimo e convencional) e técnicas modernas (plantio direto e agricultura orgânica) e, ainda, há necessidade de incorporar mais a questão da qualificação da mão de obra e investimentos em novas tecnologias e maquinário nestas microrregióes.

Considerando que no MAPITOBA existem 42 unidades de conservação (UC) e 28 áreas demarcadas como terras indígenas, sendo 17\% do território, valor superior à média nacional, e, que no Sudeste do Pará são 18 UC e 20 áreas consideradas indígenas, ocupando cerca de $35 \%$ do território dos municípios da microrregião, torna-se ainda mais relevante a utilização de técnicas agrícolas modernas e sustentáveis, para que estas áreas permaneçam preservadas (FONSECA; MIRANDA, 2014; GITE, 2016). Assim, estes resultados podem servir como base para as microrregiões adotarem medidas que auxiliem na melhoria e expansão do setor agrícola, garantindo a segurança alimentar do Norte e Nordeste e tornando a região ainda mais promissora no agronegócio a nível internacional, sem deixar de preservar os recursos naturais.

Deve-se lembrar que movimentos nesse sentido vêm sendo praticados desde 2015 no país, a partir do Decreto $\mathrm{n}^{\circ} 8.447$, de 06 de maio de 2015, que criou o Plano de Desenvolvimento Agropecuário do MAPITOBA, cujo foco é "promover e coordenar políticas públicas voltadas ao desenvolvimento econômico sustentável fundado nas atividades agrícolas e pecuárias que resultem na melhoria da qualidade de vida da população" (BRASIL, 2015a). Neste sentido também a Embrapa, junto ao Instituto Nacional de Colonização e Reforma Agrária (INCRA), vem realizando estudos desde 2014 na região para consolidar o desenvolvimento agropecuário, através do GITE. E, ainda, o mesmo GITE tem também trabalhos com foco na região Sudeste do Pará desde 2015 (GITE, 2016). 


\section{CONCLUSÃO}

Com o uso da Análise Fatorial foram identificados três fatores que representam o grau de modernização da agricultura das microrregiões de MAPITOBA e das microrregiões do Sudeste do Pará e explicaram 85,44\% da variação total dos dados. A dimensão indicadora dos fatores de produção capital e trabalho explicou 32,60\%, enquanto fatores representativos de técnicas agrícolas tradicionais sustentáveis e de técnicas modernas explicaram 30,31\% e 22,51\%, respectivamente.

Deste modo, com a utilização de variáveis diferenciadas e com foco sustentável e na melhor gestão, o modelo permitiu identificar o processo de modernização das 38 microrregiões, consideradas nesta pesquisa como nova fronteira agrícola do país. Percebe-se que nas microrregiões em análise em 2006 ainda prevaleciam técnicas tradicionais de cultivo e, mesmo com a presença de novas tecnologias ligadas à sustentabilidade ambiental, às técnicas mais modernas e à qualificação de mão de obra, a maioria das microrregiões apresentaram Índice de Modernização Agrícola (IMA) baixo.

Assim, MAPITOBA e as microrregiões do Sudeste do Pará, mesmo tendo avanços de território com cultivos agrícolas importantes para o país, como soja, milho, algodão e cana-de-açúcar, e adotando tecnologias avançadas, ainda não podem ser consideradas microrregióes modernas em termos de variáveis relacionadas à biotecnologia, nível educacional e às técnicas de cultivo de baixo impacto ambiental. Portanto, o foco das políticas governamentais deve ser para melhorar o IMA e conduzir tais microrregiões a alcançar um alto índice de modernização.

Considerando as exigências dos consumidores relacionadas à certificação, rastreabilidade e sustentabilidade dos alimentos, incorporar tecnologia torna-se fundamental em todos os elos das cadeias agroindustriais. A região tem condições propícias para agricultura moderna, tais como solos potenciais, relevo plano, dias longos, intensidade alta de sol e rotas de escoamento com distâncias menores do que as do Centro-Oeste, por exemplo, além da projeção do Ministério da Agricultura, Pecuária e Abastecimento (MAPA) para 2024/2025, de que os quatro Estados que a compõem devem produzir juntos entre 22,5 e 28 milhões de toneladas em 10 anos (BRASIL, 2015b). Diante disso, e do contexto econômico, saber os fatores 
em que cada microrregião é falha permite investir no ponto certo e avançar ainda mais em produtividade, reduzir custos e ser mais eficiente em termos de gestão das propriedades agrícolas.

\section{REFERÊNCIAS}

ALVES, V. E. L. A mobilidade sulista e a expansão da fronteira agrícola brasileira. Agrária, São Paulo, n. 2, 2005, p. 40-68. Disponível em: < http://www.revistas.usp. br/agraria/article/view/80>. Acesso em: 08 maio 2016.

ALVES, V. E. L. Mobilização e Modernização nos Cerrados Piauienses: Formação Territorial no Império do Agronegócio. Tese (Doutorado em Geografia Humana). São Paulo: Universidade de São Paulo, Faculdade de Filosofia, Letras e Ciências Humanas, Departamento de Geografia, 2006. Disponível em: < http://www.teses. usp.br/teses/disponiveis/8/8136/tde-23042007-131621/pt-br.php > . Acesso em: 07 maio 2016.

ALVES, E.; CONTINI, E.; HAINZELIN, E. Transformações da Agricultura Brasileira e Pesquisa Agropecuária. Cadernos de Ciência \& Tecnologia, Brasília, v. 22, n. 1, p. 37-51, jan./abr., 2005. Disponível em: < http://www.teses.usp.br/teses/disponiveis/8/8136/tde-23042007-131621/pt-br.php> . Acesso em: 12 jun. 2016.

BERNARDES, J. A. As Estratégias do capital no Complexo da Soja. In: CASTRO, I. E.; GOMES, P. C. C.; CORRÊA, R. L. (orgs.). Brasil: questões atuais da reorganização do território. Rio de Janeiro: Bertrand Brasil, 2002.

BRASIL. Ministério da Agricultura, Pecuária e Abastecimento. Plano setorial de mitigação e de adaptação às mudanças climáticas para a consolidação de uma economia de baixa emissão de carbono na agricultura: Plano ABC (Agricultura de Baixa Emissão de Carbono). Ministério da Agricultura, Pecuária e Abastecimento, Ministério do Desenvolvimento Agrário, coordenação da Casa Civil da Presidência da República. Brasília: MAPA/ACS, 2012. 173p. Disponível em: < http://www. mma.gov.br/clima/politica-nacional-sobre-mudanca-do-clima/planos-setoriais-de-mitigacao-e-adaptacao > . Acesso em: 07 jul. 2016. 
BRASIL. Planalto. Decreto $\mathbf{n}^{\circ} \mathbf{8 . 4 4 7}$ de 06 de maio de 2015. Dispõe sobre o Plano de Desenvolvimento Agropecuário do MATOPIBA e a criação de seu Comitê Gestor. 2015a. Disponível em: < http://www.planalto.gov.br/ccivil_03/_Ato2015-2018/2015/ Decreto/D8447.htm>. Acesso em: 24 jun. 2016.

BRASIL. Ministério da Agricultura, Pecuária e Abastecimento. Projeções do Agronegócio, Brasil 2014/15 a 2014/25: projeções de longo prazo. 6a ed. Brasília: 2015b. Disponível em: < http://www.agricultura.gov.br/arq_editor/PROJECOES DO_AGRONEGOCIO_2025_WEB.pdf >.Acesso em: 28 jun. 2016.

BUAINAIN, A. M.; PEDROSO, M. T. M.; VIEIRA JÚNIOR, P. A.; SILVEIRA, R. L. F.; NAVARRO, Z. Quais os riscos mais relevantes nas atividades agropecuárias? In: BUAINAIN, A. M.; ALVES, E.; SILVEIRA, J. M.; NAVARRO, Z. O mundo rural no Brasil do século 21: a formação de um novo padrão agrário e agrícola. Brasília: Embrapa, 2014. 1182p.

CASTILLO, R. Agronegócio e Logística em Áreas de Cerrado: expressão da agricultura científica globalizada. Revista da ANPEGE. v. 3, p. 33-43, 2007. Disponível em: < http://www.anpege.org.br/downloads/artigo_3.pdf> . Acesso em: 14 jun. 2016.

CORRÊA, A. M. C. J.; FIGUEIREDO, N. M. S. Modernização da Agricultura Brasileira no início dos anos 2000: uma aplicação da análise fatorial. Brasil, v. 10, n. 02. Revista GEPEC, 2006. Disponível em: < http://e-revista.unioeste.br/index.php/gepec/ article/view/394> . Acesso em: 05 abr. 2016.

COSTA, C. C. de M.; REIS, P. R. C.; FERREIRA, M. A. M.; MOREIRA, N. C. Modernização Agropecuária e Desempenho Relativo dos Estados Brasileiros. Agroalimentaria, Mérida, v. 18, n. 34, p. 43-56, 2012. Disponível em: < http://biblat.unam.mx/pt/ revista/agroalimentaria/articulo/modernizacao-agropecuaria-e-desempenho-relativo-dos-estados-brasileiros > . Acesso em: 15 jun. 2016.

DILLON, W. R.; GOLDSTEIN, M. Multivariate Analysis-Methods and Applications. Wiley, New York: 1984, 587p.

FONSECA, M. F.; MIRANDA, E. E. MATOPIBA: Caracterização do Quadro Agrário. Nota Técnica 6. GITE (Grupo de Inteligência Territorial Estratégica. Embrapa). Campinas: Dezembro, 2014. Disponível em: < https://www.embrapa.br/gite/publi- 
cacoes/NT6_QuadroAgrario.pdf>. Acesso em: 15 jun. 2016.

FREDERICO, S. As Cidades do Agronegócio na Fronteira Agrícola Moderna Brasileira. Caderno Prudentino de Geografia, Presidente Prudente, v. 1, n. 33, p. 5-23, jan./jul. 2011. Disponível em: < http://agbpp.dominiotemporario.com/doc/33A-2. pdf > . Acesso em: 17 maio 2016.

GAMA, Z. J. C.; SANTANA, A. C.; MENDES, F. A. T.; KHAN, A. S. Índice de desempenho competitivo das empresas de móveis da região metropolitana de Belém. Revista de Economia e Agronegócio, v. 5, n. 1, p. 127-160, 2007. Disponível em: $<$ http://www.repositorio.ufc.br/handle/riufc/1305> . Acesso em: 21 maio 2016.

GRUPO DE INTELIGÊNCIA TERRITORIAL ESTRATÉGICA - GITE. Quem somos. Disponível em: <https://www.embrapa.br/gite/index.html> Acesso em: 01 maio 2016.

HAIR, J. F.; BLACK, W. C.; BABIN, B. J.; ANDERSON, R. E.; TATHAM, R. L. Análise multivariada de dados. 6. ed. Porto Alegre: Bookman, 2009. 688p.

INSTITUTO BRASILEIRO DE GEOGRAFIA E ESTATÍSTICA - IBGE. Censo Agropecuário. 2006. Disponível em: <http://www.ibge.gov.br/home/estatistica/economia/ agropecuaria/censoagro/default.shtm. > Acesso em: 15 maio 2016.

INSTITUTO BRASILEIRO DE GEOGRAFIA E ESTATÍSTICA - IBGE. Sistema IBGE de Recuperação Automática. Pesquisa Agrícola Municipal. Disponível em: <https:// sidra.ibge.gov.br/pesquisa/pam/tabelas > . Acesso em: 20 jun. 2016.

JOHNSON, R. A.; WICHERN, D. W. Applied Multivariate Statistical Analysis. 3. ed. Englewood Cliffs, New Jersey: Prentice Hall, 1992.

MARCHÃO, R. L.; NETO, M. S.; FERREIRA, E. G.; MADARI, B. E.; SCOPEL, E.; BRITO, O. R. Evidence of limited carbon sequestration in soils under no-tillage systems in the Cerrado of Brazil, Nature, Scientific Reports6, Article number 21.450, 2016. Disponível em: < https://www.nature.com/articles/srep21450> . Acesso em: 08 jul. 2016.

MARTINS, J. S. Capitalismo e tradicionalismo: estudos sobre as contradições da sociedade agrária no Brasil. São Paulo: Pioneira, 1975. 
MIRANDA, E. E.; MAGALHÃES, L. A.; CARVALHO, C. A. Proposta de delimitação territorial do MATOPIBA. Nota Técnica 1. GITE (Grupo de Inteligência Territorial Estratégica). Embrapa. Campinas: Maio, 2014. Disponível em: < https://www.embrapa.br/gite/publicacoes/NT1_DelimitacaoMatopiba.pdf>. Acesso em: 15 abr. 2016.

MIRANDA, E. E.; MAGALHÃES, L. A.; CARVALHO, C. Um Sistema de Inteligência Territorial Estratégica Para o MATOPIBA. Nota Técnica 2. GITE (Grupo de Inteligência Territorial Estratégica). Embrapa. Campinas: Maio, 2014b. Disponível em: $<$ https://www.embrapa.br/gite/publicacoes/NT2_SITEMatopiba.pdf $>$. Acesso em: 15 abr. 2016.

MOORI, R. G.; ZILBER, M. A. Um Estudo da Cadeia de Valores com a Utilização da Análise Fatorial. Revista de Administração Contemporânea, v. 7, n. 3, 2003. Disponível em: < http://www.scielo.br/scielo.php?script=sci_arttext\&pi$\mathrm{d}=$ S1415-65552003000300007>. Acesso em: 24 abr. 2012.

MULLER, G. Complexo agroindustrial e modernização agrária. São Paulo: Hucitec/Educ., 1989.

SANTANA, A. C.; SANTANA, A. L.; SANTANA, Á. L.; COSTA, N. L.; NOGUEIRA, A. K. M. Planejamento Estratégico de uma Universidade Federal da Amazônia: aplicação da Análise Fatorial. Revista de Estudos Sociais (UFMT), v. 32, p. 183-204, 2014.

SANTOS, M. Por uma outra globalização: do pensamento único à consciência universal. Rio de Janeiro: Record, 2000.

VIEIRA FILHO, J. E. R.; SILVEIRA, J. M. F. Mudança tecnológica na agricultura: uma revisão crítica da literatura e o papel das economias de aprendizado. Revista de economia e sociologia rural, v. 50, n. 4, p. 717-738, 2012. Disponível em: <http://www.scielo.br/scielo.php?script=sci_arttext\&pid=S0103-20032012000400008> . Acesso em: 15 jun. 2016.

Recebido em: 19/04/2017 Aceito em: 02/02/2018 